\title{
Management of primary acquired melanosis (PAM) of the eye (State of Research Paper)
}

\author{
Dr. Carolina Diamandis ${ }^{1}$, Alexander Davis ${ }^{1}$, and Sophia Papadopoulou ${ }^{1}$
}

${ }^{1}$ Affiliation not available

May 17, 2021

\begin{abstract}
With regard to acquired melanosis of the conjunctiva, there is still neither a worldwide uniform nomenclature nor reliable data on how frequent this type of pigment disorder is. This is even more true for the estimation of the risk of progression into cancer as well as the clinical management of this entity. This short paper presents the current, partly contradictory scientific knowledge which is available.
\end{abstract}

\section{Hosted file}

PAM State of Research.pdf available at https://authorea.com/users/410930/articles/522209management-of-primary-acquired-melanosis-pam-of-the-eye-state-of-research-paper 